\title{
A simple method to provide positive end expiratory pressure to treat hypoxaemia in an anaesthetised Asian Elephant (Elephas maximus)
}

\begin{tabular}{|c|c|}
\hline $\begin{array}{l}\text { Authors: } \\
\text { Jessica Leung } \\
\text { Thierry Beths } \\
\text { Michael Lyncl } \\
\text { Sarah Frith } \\
\text { Sebastien H. }\end{array}$ & $\begin{array}{l}\text { (1) } \\
\text { auquier } \\
2 \text { (1) }\end{array}$ \\
\hline \multicolumn{2}{|c|}{$\begin{array}{l}\text { Affiliations: } \\
{ }^{1} \text { UVet Animal Hospital, } \\
\text { Faculty of Veterinary and } \\
\text { Agricultural Sciences, The } \\
\text { University of Melbourne, } \\
\text { Werribee, Australia }\end{array}$} \\
\hline \multicolumn{2}{|c|}{$\begin{array}{l}{ }^{2} \text { Faculty of Veterinary and } \\
\text { Agricultural Sciences, Zoos } \\
\text { Victoria, Parkville, Australia }\end{array}$} \\
\hline \multicolumn{2}{|c|}{$\begin{array}{l}\text { Corresponding author: } \\
\text { Sebastien Bauquier, } \\
\text { bauquier@unimelb.edu.au }\end{array}$} \\
\hline $\begin{array}{l}\text { Dates: } \\
\text { Received: } 23 \\
\text { Accepted: } 31 \\
\text { Published: } 19\end{array}$ & $\begin{array}{l}\text { ept. } 2020 \\
\text { Mar. } 2021 \\
\text { May } 2021\end{array}$ \\
\hline \multicolumn{2}{|c|}{$\begin{array}{l}\text { How to cite this article: } \\
\text { Leung, J., Beths, T., Lynch, M., } \\
\text { Frith, S. \& Bauquier, S.H., } \\
\text { 2021, 'A simple method } \\
\text { to provide positive end } \\
\text { expiratory pressure to } \\
\text { treat hypoxaemia in an } \\
\text { anaesthetised Asian Elephant } \\
\text { (Elephas maximus)', Journal } \\
\text { of the South African } \\
\text { Veterinary Parasitology } \\
\text { 92(0), a2118. https://doi. } \\
\text { org/10.1016/jsava.v92i0.2118 }\end{array}$} \\
\hline \multicolumn{2}{|c|}{$\begin{array}{l}\text { Copyright: } \\
\text { (C) 2021. The Authors. } \\
\text { Licensee: AOSIS. This work } \\
\text { is licensed under the } \\
\text { Creative Commons } \\
\text { Attribution License. }\end{array}$} \\
\hline \multicolumn{2}{|l|}{ Read online: } \\
\hline 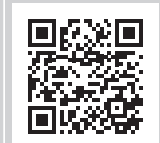 & $\begin{array}{l}\text { Scan this QR } \\
\text { code with your } \\
\text { smart phone or } \\
\text { mobile device } \\
\text { to read online. }\end{array}$ \\
\hline
\end{tabular}

\section{Authors:}

Thierry Beths ${ }^{1}$

Michael Lynch ${ }^{2} \mathbb{0}$

Sarah Frith ${ }^{2}$

Sebastien $\mathrm{H}$. Bauquier ${ }^{1}$

Affiliations:

Agricultural Sciences, The University of Melbourne, Agricultural Sciences, Zoos

Corresponding author:

Sebastien Bauquier

Dates:

Accepted: 31 Mar. 2021

How to cite this article: Leung, J., Beths, T., Lynch, M.

Frith, S. \& Bauquier, S.H.

2021, 'A simple method

expiratory pressure to

treat hypoxaemia in an

of the South African

Veterinary Parasitology

92(0), a2118. https://doi.

016/jsava.v92i0.2118

Copyright:

Licensee: AOSIS. This work

is licensed under the

Creative Commons

Attribution License.

mobile device
Hypoxaemia is a common complication in anaesthetised or immobilised elephants. It is presumably because of hypoventilation and ventilation-perfusion mismatch. To prevent hypoxaemia, orotracheal intubation and positive pressure ventilation are recommended. This case report describes a hypoxaemic period despite positive pressure ventilation in a 46-year-old female Asian elephant (Elephas maximus) anaesthetised with azaperone-etorphine, medetomidine and an etorphine constant rate infusion in lateral recumbency for a dental procedure. The hypoxaemia was corrected utilising positive end-expiratory pressure (PEEP) of $5 \mathrm{~cm}-10 \mathrm{~cm} \mathrm{H} \mathrm{H}_{2}$, a technique that has not previously been reported in the management of anaesthetised elephants. PEEP decreases atelectasis, shunt fraction, and increases lung compliance. Positive end-expiratory pressure was achieved by partial occlusion of the tailpiece of a manually triggered demand valve ventilator during expiration. This is a simple effective method of generating PEEP and correcting hypoxaemia without the need for any additional specialised equipment. However, PEEP decreased arterial blood pressure and should be implemented with caution if arterial blood pressure is not monitored.

Keywords: anaesthesia; Asian elephant; Elephas maximus; hypoxaemia; Positive endexpiratory pressure; ventilation.

\section{Introduction}

Hypoxaemia is a frequently reported complication in captive and free-ranging immobilised elephants (Honeyman, Pettifer \& Dyson 1992; Horne \& Loomis 2014; Stegmann, Grobler \& Zuba 2014). Apart from the use of intermittent positive pressure ventilation (IPPV), there is scarce literature regarding its prevention and correction (Horne \& Loomis 2014; Horne, Tchamba \& Loomis 2001; Stegmann et al. 2014). This case report describes the use of positive end-expiratory pressure (PEEP) to alleviate hypoxaemia in a laterally recumbent, anaesthetised Asian elephant (Elephas maximus).

\section{Patient presentation}

A 46-year-old female E. maximus weighing $3340 \mathrm{~kg}$ (several months prior to anaesthesia) was anaesthetised for extraction of the right mandibular molar 3 . Food had been withheld for $17 \mathrm{~h}$ and water withheld for $15 \mathrm{~h}$ prior to anaesthesia. The elephant was immobilised with $3 \mu \mathrm{g} / \mathrm{kg}$ etorphine IM (Etorphine, Wildlife Pharmaceuticals, South Africa) and $9 \mu \mathrm{g} / \mathrm{kg}$ azaperone IM (Stresnil, Elanco, Australia) administered by hand injection. Fifteen minutes after initial immobilisation agents were delivered, profound sedation was achieved and the animal was guided into left lateral recumbency onto a deep sand bed using a rope casting technique. The left auricular vein was catheterised and $1.2 \mu \mathrm{g} / \mathrm{kg}$ medetomidine intravenous (IV) (Medetomidine, Ilium, Glendenning, Australia) was administered. Anaesthesia was maintained using an etorphine constant rate infusion $(0.6 \mu \mathrm{g} / \mathrm{kg} / \mathrm{h}-1.5 \mu \mathrm{g} / \mathrm{kg} / \mathrm{h} \mathrm{IV})$. The etorphine was diluted in $1 \mathrm{~L}$ of lactated ringers solution and run through a fluid pump to ensure it was delivered at a constant rate. Heart rate $(\mathrm{HR})$, pulse oximetry $\left(\mathrm{SpO}_{2}\right)$, respiratory rate $(\mathrm{RR})$, endtidal $\mathrm{CO}_{2}$, inspired oxygen concentration $\left(\mathrm{FiO}_{2}\right)$, electrocardiography and invasive blood pressure (BP) (18 g catheter in the auricular artery) were monitored using a calibrated multiparameter anaesthetic monitor (Mindray, Notting Hill, Victoria, Australia). Arterial blood gas tests were performed using a handheld blood gas monitor iStat, Abbott Laboratories, United States (US). 
TABLE 1: Cardiorespiratory variables over the duration of the anaesthetic for an elephant anaesthetised with etorphine-azaperone, medetomidine and an etorphine constant rate infusion.

\begin{tabular}{|c|c|c|c|c|c|c|c|c|}
\hline Time & Event & HR & $\mathbf{R R}$ & $\mathrm{SPO}_{2}$ & $\mathrm{ETCO}_{2}$ & MAP & $\mathrm{PaO}_{2}$ & $\mathrm{PaCO}_{2}$ \\
\hline 9:07 & Etorphine/azaperone injection & - & - & - & - & - & - & - \\
\hline $9: 22$ & Recumbency achieved & - & - & - & - & - & - & - \\
\hline 9:23 & Cannulation of auricular vein, $4 \mathrm{mg}$ medetomidine IV & 39 & 5 & 97 & - & - & - & - \\
\hline 9:27 & First intubation attempt & 42 & 0 & 96 & - & - & - & - \\
\hline 9:29 & Second intubation attempt with smaller ETT & 40 & 0 & 97 & - & - & - & - \\
\hline 9:30 & Atipamezole $20 \mathrm{mg} \mathrm{IV}$ & 42 & 0 & 96 & - & - & - & - \\
\hline 9:31 & Intubation & 37 & 0 & 99 & - & - & - & - \\
\hline $9: 32$ & Commence IPPV & 37 & 6 & 100 & 34 & - & - & - \\
\hline 9:37 & Commence etorphine CRI & 32 & 6 & 95 & 30 & - & - & - \\
\hline 9:55 & Arterial line placement & 46 & 7 & 100 & 31 & 172 & 78 & 47.2 \\
\hline 10:10 & Commence dental procedure & 47 & 7 & 97 & 28 & 170 & - & - \\
\hline 10:16 & Desaturation & 40 & 7 & 92 & 30 & 138 & 76 & 56.8 \\
\hline $10: 25$ & Extubate because of leaking ETT & 54 & - & 88 & - & 132 & - & - \\
\hline 10:31 & Reintubate with larger ETT & 50 & 7 & 86 & 23 & 120 & - & - \\
\hline $10: 40$ & Before start of PEEP & 33 & 7 & 89 & 25 & 91 & 49 & 54.9 \\
\hline $10: 50$ & Removed arterial line & - & 7 & 94 & 19 & 70 & 59 & 23.6 \\
\hline 10:55 & Removed remainder of monitoring & - & - & 97 & - & - & - & - \\
\hline $11: 00$ & End anaesthesia, administered naltrexone and atipemazole & - & - & - & - & - & - & - \\
\hline 11:02 & Standing & - & - & - & - & - & - & - \\
\hline
\end{tabular}

$\mathrm{EtCO}_{2}$, end-tidal carbon dioxide; $\mathrm{ETT}$, endotracheal tube; $\mathrm{HR}$, heart rate; $\mathrm{MAP}$, mean arterial pressure; $\mathrm{PaCO}_{2}$, partial pressure of arterial carbon dioxide; PaO ${ }_{2}$, partial pressure of arterial oxygen; $\mathrm{RR}$, respiratory rate; $\mathrm{SpO}_{2}$, oxygen saturation; IPPV, intermittent positive pressure ventilation; PEEP, positive end-expiratory pressure; CRI, constant rate infusion.

As a result of difficulties with intubation and a period of apnoea that developed after the medetomidine administration, $6 \mu \mathrm{g} / \mathrm{kg}$ atipamezole was administered IV (Atipamezole, Ilium, Australia). Shortly after reversal, a 30mm internal diameter (ID) cuffed orotracheal tube was placed and connected to a manually triggered MegaVertebrate demand ventilator (In Case of Anesthesia, US). With a peak inspiratory pressure (PIP) of $15 \mathrm{~cm} \mathrm{H}_{2} \mathrm{O}, \mathrm{RR}$ of 7 and an inspiratory: expiratory ratio (I:E) of $1: 1$, it allowed the maintenance of normocapnia $\left(\mathrm{EtCO}_{2}\right.$ between 35 millimetre of mercury [ $\mathrm{mmHg}$ ] and $45 \mathrm{mmHg}$ ), while providing a $\mathrm{FiO}_{2}$ of about $33 \%$.

After $1 \mathrm{~h}$ into the anaesthetic, the $\mathrm{SpO}_{2}$ value decreased from $100 \%$ to $92 \%$. A leak around the orotracheal tube was detected and another 30-mm ID tube with a slightly larger external diameter was placed. Although the PIP was increased to $20 \mathrm{~cm} \mathrm{H}_{2} \mathrm{O}$, the $\mathrm{SpO}_{2}$ value declined between $86 \%$ and $89 \%$. An arterial blood gas analysis confirmed a diagnosis of

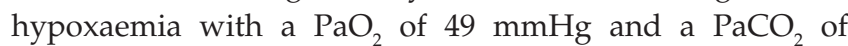
$55 \mathrm{mmHg}$ (see Table 1).

To treat the hypoxemia, it was decided to add PEEP. At the end of the inspiration phase, the anaesthetist let the air pressure decrease until it reached $5 \mathrm{~cm}-10 \mathrm{~cm} \mathrm{H}_{2} \mathrm{O}$. At that time, using his hand, the anaesthetist applied PEEP by blocking the ventilator's exhaust tailpiece to prevent the air pressure from decreasing further until the next breath. The PIP, RR and the I:E ratio remained unchanged at $20 \mathrm{~cm} \mathrm{H}_{2} \mathrm{O}$, 7 breaths a minute and about 3.5:5, respectively. Within $7 \mathrm{~min}$, the $\mathrm{PaO}_{2}$ increased to $59 \mathrm{mmHg}\left(\mathrm{SpO}_{2}\right.$ of $\left.92 \%\right)$, and shortly after, the $\mathrm{SpO}_{2}$ reached $97 \%$; however, further blood gas analysis was not available.

While oxygenation improved with PEEP, BP declined from a mean arterial pressure of $132 \mathrm{mmHg}$ immediately before PEEP to as low as $70 \mathrm{mmHg}$ during PEEP. In preparation for recovery, the arterial catheter was removed and PEEP was discontinued because of the risk of unmonitored hypotension.

\section{Discussion}

The potent opioid etorphine is often used to anesthetise elephants either alone or in combination with other drugs (Honeyman et al. 1992; Horne et al. 2001; Stegmann et al. 2014). It often causes hypoventilation and moderate to severe hypoxaemia (Horne \& Loomis 2014; Stegmann et al. 2014). In conscious E. maximus, lateral recumbency for $15 \mathrm{~min}$ is also associated with a significant decrease in $\mathrm{PaO}_{2}$ when compared with standing. This reduction in $\mathrm{PaO}_{2}$ can be as significant as $30 \%$ but is usually not accompanied by any change in $\mathrm{PaCO}_{2}$ (Honeyman et al. 1992; Isaza et al. 2003). As such, hypoventilation is hypothesised to contribute less to hypoxaemia in conscious recumbent elephants than ventilation/perfusion (V/Q) mismatch and pulmonary shunting, similar to horses (Horne \& Loomis 2014). In the latter, the degree of V/Q mismatch correlates positively with increasing body mass and being influenced by the shape of the thoracoabdominal contour (Moens et al. 1998). Therefore, the physical attributes of elephants, including a high body mass and extremely oblique set diaphragm, may contribute to the rapid formation of V/Q mismatch (Horne \& Loomis 2014; Stegmann et al. 2014). The use of etorphine may further exacerbate $\mathrm{V} / \mathrm{Q}$ mismatch as it is a known cause of pulmonary hypertension in other species (Meyer et al. 2015). Extreme pulmonary hypertension may result in right to left shunt, thus contributing to hypoxaemia.

As a result of the use of potent respiratory depressants and the rapid development of $\mathrm{V} / \mathrm{Q}$ mismatch, oxygen 
supplementation is recommended for all immobilised or anaesthetised elephants (Horne \& Loomis 2014). Although elephants are primarily nasal breathers, oxygen insufflation via the trunk is usually unsuccessful in preventing hypoxaemia (Horne \& Loomis 2014; Stegmann et al. 2014). Intermittent positive pressure ventilation through an orotracheal tube is therefore the preferred method of ventilation with multiple modes of IPPV reported in that species. Such methods of IPPV include the use of modified leaf blowers to deliver room air in the field, high flow demand valves connected in series to deliver $100 \%$ oxygen and customised bellow driven ventilators for use in a clinic environment (Horne \& Loomis 2014; Horne et al. 2001).

In this case, a combination of drug-induced hypoventilation and the development of V/Q mismatch are the likely causes of the observed hypoxaemia. Correction of hypoventilation by providing IPPV and increasing PIP was unsuccessful in correcting hypoxaemia. In anaesthetised horses, atelectasis forms rapidly, and the early implementation of IPPV is recommended to maintain and improve oxygenation (Moens et al. 1995, 1998; Wilson \& Soma 1990). The delay in implementing IPPV because of difficulties in intubation and the initial period of apnoea may have contributed to the development of atelectasis, V/Q mismatch and consequently hypoxaemia in this case. The anaesthetist was unable to increase PIP past $20 \mathrm{~cm} \mathrm{H}_{2} \mathrm{O}$, which did not allow for a proper recruitment manoeuvre and was followed by a further decrease in $\mathrm{SpO}_{2}$.

This case utilised a commercially available assisted demand ventilator. The design of this specific ventilator is such that rapid and high flow oxygen delivery into the ventilator generates negative pressure at the tailpiece of the ventilator and draws in atmospheric air through entrainment. The increase of gas flow permits a quicker delivery of the required tidal volume. The resulting $\mathrm{FiO}_{2}$ was $33 \%$, although a $\mathrm{FiO}_{2}$ of $42 \%$ is reported by the manufacturer (In Case of Anaesthesia, n.d.). As high $\mathrm{FiO}_{2}$ is associated with increased shunt fraction in other species, the lower $\mathrm{FiO}_{2}$ provided by this ventilator may have been beneficial in preventing further atelectasis (De Monte et al. 2013; Osbertg et al. 2017).

Positive end-expiratory pressure, which is defined as the residual alveolar pressure above atmospheric pressure at the end of expiration, improved oxygenation (Ambrosio et al. 2013; Moens et al. 1998). The mechanism by which PEEP achieved this is multifactorial. It includes increased alveolar pressures to reopen alveoli and prevent alveoli collapse, decreased work of breathing, increased functional residual capacity and altering the centre of distribution of ventilation within the lungs (Ambrosio et al. 2013; De Monte et al. 2013).

Positive end-expiratory pressure improves pulmonary gas exchange in multiple species under anaesthesia (Ambrosio et al. 2013, 2017; Osbertg et al. 2017). In humans, a PEEP around $6 \mathrm{~cm} \mathrm{H}_{2} \mathrm{O}$ prevents atelectasis, although a higher PEEP is required to reopen closed alveoli (Osbertg et al. 2017).
In dogs, a PEEP at $10 \mathrm{~cm} \mathrm{H}_{2} \mathrm{O}$ results in a significant reduction of atelectasis and an increase in lung volume by up to $60 \%$, while in horses, titration of the PEEP improves oxygenation, reduces shunt fraction and increases lung compliance (De Monte et al. 2013; Moens et al. 1998).

On a modern mechanical ventilator, PEEP is a basic setting that applies pressure at the end of expiration. Otherwise, commercial PEEP valves or handmade water column can be adapted onto the expiratory limb of the circuit or the scavenge tubing of the anaesthesia machine (Allison et al. 2017). In this case, suitable PEEP valves were not available, and use of a water column was inappropriate because of the risk of water being funnelled into the circuit. Covering the tailpiece of the ventilator at expiration was effective at generating PEEP. This is a simple method of generating PEEP without the need for any specialised equipment.

The use of PEEP in elephants may be of particular use in recruiting collapsed alveoli and improving oxygenation because of their unique respiratory system. Elephants lack a pleural space, instead, they possess a distensible collagen fibre network that adheres to the pleura of the chest wall. In addition, the parenchyma itself is supported by an elastic septum that limits alveoli collapse (Browne et al. 1997). These anatomical features may explain the effective recruitment of alveoli and improved oxygenation when applying low levels of PEEP in this elephant. Additionally, following recruitment of the alveoli, the application of PEEP or the reduction of the $\mathrm{FiO}_{2}$ to $40 \%$ was shown to improve and maintain oxygenation and respiratory compliance in dogs (De Monte et al. 2013). The combination of PEEP and reduced $\mathrm{FiO}_{2}$ provided by the ventilator may have aided the improved oxygenation in this elephant.

As a result of the increased intrathoracic pressures generated by PEEP, cardiac output and consequently, BP often declines (Luecke \& Pelosi 2005; Wilson \& Soma 1990). This is primarily because of a decrease in venous return and thus ventricular stroke volume (Luecke \& Pelosi 2005). In this case, PEEP resulted in a reduction of $\mathrm{BP}$ by nearly $50 \%$ and thus PEEP was titrated to avoid further decline in BP while maintaining oxygenation. Arterial BP should therefore be monitored closely when PEEP is implemented.

Although the application of PEEP may impair cardiac output, the period of hypotension in this animal may have been exacerbated by other factors. The withholding of water prior to anaesthesia may have produced a mild hypovolaemia resulting in hypotension. In addition, the use of azaperone and atipamezole may have caused vasodilation, thus further reducing BP. The aetiology of the hypotension was likely multifactorial and PEEP impaired the ability of the animal to compensate adequately for its impaired cardiovascular status.

In conclusion, PEEP could easily be generated on the MegaVertebrate demand ventilator and was effective at improving 
oxygenation in laterally recumbent E. maximus undergoing general anaesthesia.

\section{Acknowledgements Competing interests}

The authors declare that they have no financial or personal relationships that may have inappropriately influenced them in writing this article.

\section{Authors' contributions}

J.L., M.L., S.F. and S.H.B. participated in the collection of data. J.L., T.B., M.L., S.F. and S.H.B. participated in the writing or editing of the manuscript.

\section{Ethical considerations}

Ethical approval was not required for this case report. This article followed all ethical standards for research without direct contact with human or animal subjects.

\section{Funding information}

This research received no specific grant from any funding agency in the public, commercial or not for profit sectors.

\section{Data availability}

The data that support the findings of this study are available from the corresponding author, S.H.B., upon reasonable request.

\section{Disclaimer}

The views and opinions expressed in this article are those of the authors and do not necessarily reflect the official policy or position of any affiliated agency of the authors.

\section{References}

Allison, A., Huizing, X., Jolliffe, C. \& Schaafsma, I., 2017, 'Effect of fixed value positive end expiratory pressure valves on canine thoracic volume and atelectasis' Journal of Small Animal Practice 58(11), 645-651. https://doi.org/10.1111/ jsap. 12710
Ambrosio, A.M., Carvalho-Kamakura, T.P.A., Ida, K.K., Varela, B., Andrade, F., Faco, L.L. et al., 2017, 'Ventilation distribution assessed with electrical impedance tomography and the influence of tidal volume, recruitment and positive endtomography and the influence of tidal volume, recruitment and positive end-
expiratory pressure in isoflurane-anaesthetised dogs', Veterinary Anaesthesia and Analgesia 44(2), 254-263. https://doi.org/10.1016/j.vaa.2016.06.003

Ambrosio, A.M., Ida, K.K., Souto, M.T., Oshiro, A.H. \& Fantoni, D.T., 2013, 'Effects of positive end-expiratory pressure titration on gas exchange, respiratory mechanics and hemodynamics in anaesthetised horses', Veterinary Anaesthesia and Analgesia 40(6), 564-572. https://doi.org/10.1111/vaa.12068

Browne, R.E., Butler, J.P., Godleski, J.J. \& Loring S.H., 1997, 'The elephant's respiratory system: Adaptations to gravitational stress', Respiration Physiology 109(2), 177-194. https://doi.org/10.1016/s0034-5687(97)00038-8

De Monte, V., Grasso, S., De Marzo, C., Crovace, A. \& Staffieri F., 2013, 'Effects of reduction of inspired oxygen fraction or application of positive end-expiratory pressure after an alveolar recruitment maneuver on respiratory mechanics, gas exchange, and lung aeration in dogs during anesthesia and neuromuscular blockade', American Journal of Veterinary Research 74(1), 25-33. https://doi. org/10.2460/ajvr.74.1.25

Honeyman, V.L., Pettifer, G.R. \& Dyson, D.H, 1992, 'Arterial blood pressure and blood gas values in normal standing and laterally recumbent African (Loxodonto Africana) and Asian (Elephas maximus) elephants', Journal of Zoo and Wildlife Medicine 23(2), 205-210.

Horne, W.A. \& Loomis, M.R., 2014, 'Elephants and Hyrax', in G. West \& D.J. Heard (eds.), Zoo animal and wildlife immobilization and anesthesia, 2 nd edn., pp. 507-521, Wiley, Ames, lowa.

Horne, W.A., Tchamba, M.N. \& Loomis M.R., 2001, 'A simple method of providing intermittent positive-pressure ventilation to etorphine immobilised elephants (Loxodonta africana) in the field', Journal of Zoo and Wildlife Medicine 32(4) 519-522.https://doi.org/10.1638/1042-7260(2001)032[0519:ASMOPI]2.0.CO;2

In Case of Anesthesia, n.d., The Elephant mega-vertebrate demand ventilator, viewed 03 August 2019, from http://www.incaseofanesthesia.com/Product_ Information.php.

Isaza, R., Behnke, B.J., Bailey, J.K., McDonough, P., Gonzalez, N.C. \& Poole, D.C., 2003 'Arterial blood gas control in the upright versus recumbent Asian elephant', Respiratory Physiology \& Neurobiology 134(2), 169-176. https://doi.org/10.1016/ Respiratory Physiology \&

Luecke, T. \& Pelosi, P., 2005, 'Clinical review: Positive end- expiratory pressure and cardiac output', Critical Care 9(6), 607-692. https://doi.org/10.1186/cc3877

Meyer, L.C., Hetem, R.S., Mitchell, D. \& Fuller A., 2015, 'Hypoxia following etorphine administration in goats (Capra hircus) results more from pulmonary hypertension than from hypoventilation', BMC Veterinary Research 11(1), 18. https://doi. org/10.1186/s12917-015-0337-5

Moens, Y., Lagerweij, E., Gootjes, P. \& Poortman, J., 1995, 'Distribution of inspired gas to each lung in the anaesthetised horse and influence of body shape', Equine Veterinary Journal 27(2), 110-116. https://doi.org/10.1111/j.2042-3306.1995. tb03045.x

Moens, Y., Lagerweij, E., Gootjes, P. \& Poortman, J., 1998, 'Influence of tidal volume and positive end-expiratory pressure on inspiratory gas distribution and gas exchange during mechanical ventilation in horses positioned in lateral exchange during mechanical ventilation in horses positioned
recumbency', American Journal of Veterinary Research 59(3), 307-312.

Osbertg, E., Auner, U., Enlund, M., Zetterstrom, H. \& Edmark, L., 2017, 'Minimizing atelectasis formation during general anesthesia- oxygen washout is a nonessential supplement to PEEP', Upsala Journal of Medical Science 122(2), 92-98. https://doi.org/10.1080/03009734.2017.1294635

Stegmann, G.F., Grobler, D. \& Zuba, J., 2014, 'Field anaesthesia of the African elephant (Loxodonta Africana)', South African Journal of Anaesthesia and Analgesia 20(1), 95-96. https://doi.org/10.1080/22201173.2014.10844576

Wilson, D.V. \& Soma, L.R, 1990, 'Cardiopulmonary effects of positive end-expiratory pressure in anaesthetised, mechanically ventilated ponies', American Journal of Veterinary Research 51(5), 734-739. 